\title{
Preparing for inactivity: how insectivorous bats deposit a fat store for hibernation
}

\author{
John R. Speakman* and Angela Rowland \\ Aberdeen Centre for Energy Regulation and Obesity, Department of Zoology, University of Aberdeen, Aberdeen AB24 2TZ, UK
}

\begin{abstract}
During late autumn insectivorous bats must deposit a fat store to cover their energy demands throughout the period of hibernation, yet the density of aerial insects by this time has aiready declined from its peak in midsummer. Krzanowski (1961) suggested that bats are able to deposit a fat store by manipulating their energy expenditure; specifically by selecting cold roosting locations rather than warm roosts, and depressing their body temperatures during the day roosting period. It was hypothesized that these behavioural changes result in very low daily energy demands, and despite reduced food intake the animals are still able to gain body fat. We made several tests of this hypothesis. First, we explored the thermo-selection behaviour of long-eared bats (Plecotus auritus) in the summer and in the pre-hibernal period. We found that in summer bats preferred temperatures of about $32-35^{\circ}$ (about thermoneutral), but in the pre-hibernal period they preferred much colder temperatures of about $10^{\circ}$. Second, using open-flow respirometry we found that in the cold pre-hibernal bats entered torpor for an average of $14 \mathrm{~h}$ each day. Compared with bats held at $30^{\circ}$ (that did not go torpid), the bats at $7^{\circ}$ expended less energy. The extent of saving was sufficient to positively affect their mass balance, despite the fact that bats at lower temperature also had reduced digestive efficiencies. Our findings support the hypothesis that during the pre-hibernal period insectivorous bats manipulate their mass balance primarily by alterations in their energy expenditure, specifically utilizing energy-sparing mechanisms such as torpor.
\end{abstract}

Hibernation: Thermo-selection: Torpor: Energy expenditure: Insectivorous bats

For endothermic animals that live in temperate and arctic regions, winter represents a serious challenge. In particular it poses endothermic animals with two problems. The first problem is the decline in ambient temperatures. Even in the UK, with its oceanic climate, the difference between average daily summer and winter temperatures is about $15^{\circ}$. In more continental regions the differences can be as great as $50^{\circ}$ (Oliver \& Fairchild, 1984). These changes in ambient temperature mean that unless animals respond in some way, the energy requirements to sustain their body temperatures will be greatly increased. This effect can be illustrated by considering the costs of heating a typical house in the UK. Houses are typically maintained at about $20-25^{\circ}$ throughout the year, and there are generally no structural alterations made to them in winter to reduce the levels of heat loss. Consequently, fuel bills in winter may exceed those in summer by 5-6-fold (Speakman, 1997). This is also reflected in the seasonal changes in UK gas consumption, which are 3-3.5 times greater in December and January than they are in July (Cameron, 1994). As endothermic animals also regulate their body temperatures at relatively high levels, when compared with ambient temperatures in the arctic and temperate zones, if they did not respond to the change in seasons, we might expect that they too would experience an analogous degree of change in energy demands between summer and winter.

The potentially increased energy demands in winter are exacerbated by the second problem, which is the winter decline in primary productivity. This decline permeates through the entire ecosystem to reduce the availability of food at all the trophic levels. Moreover, activity of invertebrates and exothermic vertebrates is also reduced at the lower ambient temperatures, further depressing food availability to predators which feed on these animals as prey. Thus, at the very time when energy demands are potentially greatly increased, the supply of food to meet those demands is reduced. It would be like an employer deciding to pay ten times more in the summer than in winter 
despite the fact that household heating bills are five times greater in winter.

Animals respond to these problems in three basic ways. The first response is simply to run away from the problem. By migrating to warmer and more productive climates animals that migrate simply avoid the energetic challenge that winter poses. The distances that animals need to move to avoid the temperate and arctic winter are great. Generally animals need to move several thousand kilometres to subtropical or tropical regions to fully avoid the problem. This means that migration as a strategy is really only viable for animals that can fly. Terrestrial locomotion, particularly for small animals, is just too slow for a return journey to be feasible. For example, wheel-running experiments suggest that the maximum distance a short-tailed field vole (Microtus agrestis) can travel in a night is about $15 \mathrm{~km}$ (P Redman and IR Speakman, unpublished results). For a small vole to make a return journey of $3000 \mathrm{~km}$, therefore, would take it about $400 \mathrm{~d}$, without considering how it might successfully negotiate hazards such as rivers and lakes. By contrast, many small birds can fly unassisted by winds at $10-15 \mathrm{~m} / \mathrm{s}$, and with tail winds may travel at ground speeds of $20-25 \mathrm{~m} / \mathrm{s}$ (Alerstam, 1990). By flying for $15 \mathrm{~h}$ a bird could potentially cover over $1000 \mathrm{~km}$ and would be unaffected by landscape barriers, making long-distance migration a viable strategy. Between one-third and half the birds in the temperate and arctic zones are migrational (Baker, 1980).

The second tactic animals employ to meet the challenge of winter is to remain in the same area, sustaining euthermic body temperatures, but reducing the costs of being homeothermic by changing their physiology, morphology and behaviour. Many animals, for example, increase the insulation of their pelage in winter to reduce heat loss (Hart, 1957). Some animals become more social and huddle together to conserve heat (Karasov, 1983; Berteaux et al. 1996). Many animals reduce their body sizes to reduce winter energy demands, and in some animals (e.g. shrews; Soricidae) this reduction even involves a reduction in their skeletal size (Heldmaier, 1989). These acclimatization responses to winter mean that energy demands for these animals generally do not increase between summer and winter, and may even be reduced. This allows the animals to sustain an energy balance despite the reduced food supply. Some animals, which remain euthermic and active in winter (e.g. titmice; Paridae), store food (e.g. nuts and berries) during the summer to supplement the resources that are available over the winter.

Finally, the third strategy that endothermic animals employ is to abandon euthermic body temperature regulation altogether and enter hibernation. This has a massive impact on daily energy requirements, reducing them by up to two orders of magnitude (Hock, 1951; Kayser, 1961). However, by reducing body temperature the animals also become incapable of activity, and are therefore unable to feed. Although animals periodically arouse from hibernation (Twente \& Twente, 1965; Daan, 1973; Funakoshi \& Uchida, 1978; Wang, 1978; Geiser \& Kenagy, 1988) and are sometimes observed to feed when aroused (O'Farrell \& Bradley, 1970; Avery, 1985), the function of these arousals does not appear to be to acquire the reserves necessary to sustain the energy demands of hibernating. Rather, arousals allow animals to perform other functions such as drinking (Speakman \& Racey, 1989; Thomas \& Cloutier, 1992; Thomas, 1995; Thomas \& Geiser, 1997) or sleeping (Strijkstra \& Daan, 1997), and those animals which feed when aroused only do so to offset part of the energy cost of the arousal. In fact, in many circumstances hibernating animals cannot feed when aroused simply because there is no food available for them to feed on, yet they still arouse. Since the reserves necessary to sustain animals throughout hibernation are not acquired during the hibernal period, animals must store the reserves before hibemation commences. Storage may occur outside the body (for example, see Lyman, 1954; Livoreil \& Baudoin, 1996), but more generally hibernating animals deposit an internal fat store which they systematically deplete over the course of the winter lethargy (for example, see Krulin \& Sealander, 1972; Avery, 1985). Fat storage is probably more effective for hibernators because they are not awake to defend an external store from thieves, and the internal store is available to support the low metabolic rate of the hibernating animal without the need to periodically arouse and feed. In addition, because they are not routinely active, there are no disadvantages connected with carrying around fat, such as increased risks of predation (Witter et al. 1994). Starvation due to reserve depletion during hibernation has been reported to be a major cause of mortality in some populations of hibernating bats (Davis \& Hitchcock, 1965), and consequently it is widely suggested that bats entering hibernation with larger stores of energy are more likely to survive (Beer \& Richards, 1956; Davis \& Hitchcock, 1965; Davis, 1970; Ransome, 1971; Thomas et al. 1990).

For many bat species, however, there is a problem with depositing a substantial fat store before hibernation. Consequently, bats deposit relatively smaller stores than hibernating rodents (Fisher \& Mannery, 1967, cited by Thomas \& Cloutier, 1992). The major problem is that generally by the time they have completed their breeding activities in the summer, the temperature and food supply have already decreased quite substantially relative to those available at the summer peak. An example of this is illustrated in Fig. 1(a). This shows the aerial insect density throughout a typical summer in the temperate zone (Aberdeen $57^{\circ} \mathrm{N}$ ). These insects are the food source for aerial insectivorous bats. By October the aerial insect abundance is only about one-quarter to one-tenth the levels at the peak of summer. Moreover, temperature records reveal that by October the ambient temperature is also well reduced relative to peak summer levels (Fig. 1(b)). Yet it is precisely at this time of year that aerial insectivorous bats are depositing the fat store that will enable them to survive throughout the winter in hibernation (Baker et al. 1968; Ewing et al. 1970; Krulin \& Sealander, 1972). In the present paper we address the problem of how insectivorous bats manage to deposit a fat store at this time of year.

\section{Hypothesis}

A general hypothesis for how small insectivorous bats manage to deposit fat stores (based on that of Krzanowski, 1961 ) is that they abandon their summer roosting sites, 

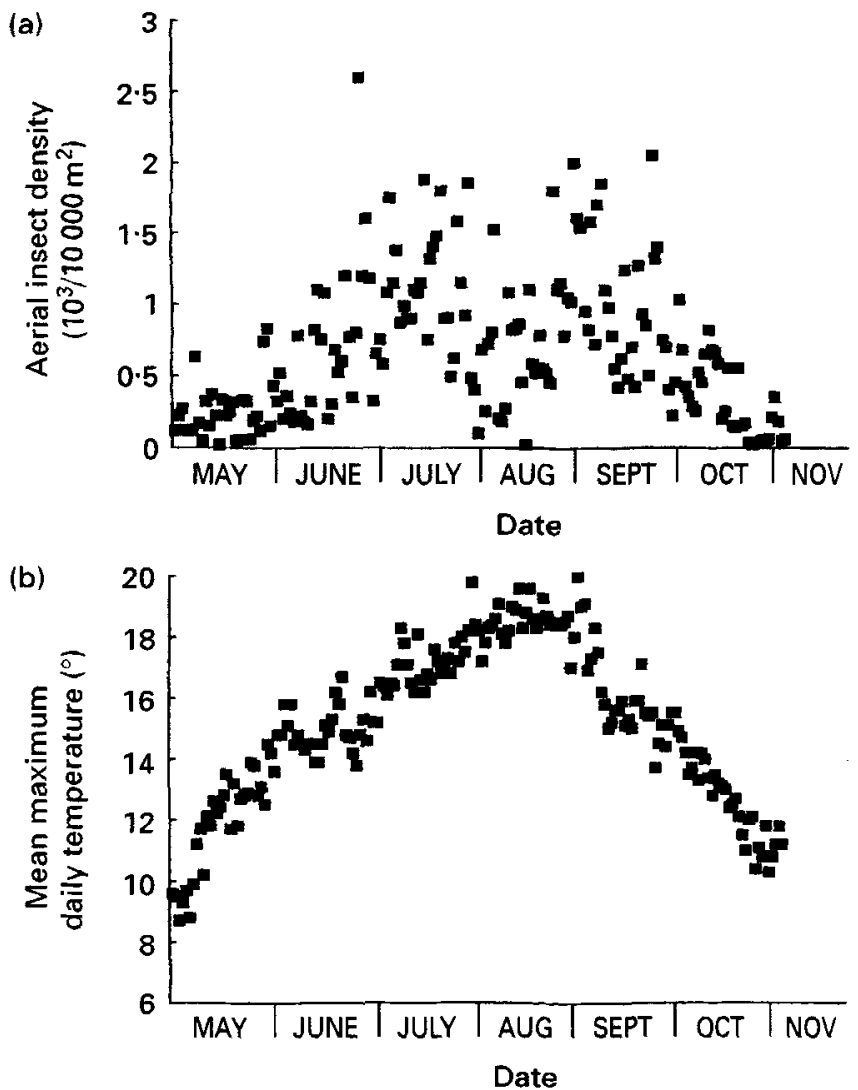

Fig. 1. (a) Aerial insect densities, measured using a Johnson Taylor suction trap running throughout the hours of darkness, throughout a typical summer in the temperate zone (Aberdeen). Apart from a period in late July-August when densities were depressed because of a period of bad weather the densities peak in midsummer and by Octo. ber have declined to between one-quarter and one-tenth the peak levels. (b) Seasonal variation in mean maximum daily ambient temperature averaged over a period of 8 years $(1978-1986)$ at the same site as where the insects were trapped.

which are generally warm structures, and preferentially select much colder locations in which to spend the daytimes. In these cold sites the animals temporarily suspend thermoregulation, but for less than a single day (a sort of mini-hibernation), which is generally termed daily torpor. It is hypothesized that by selecting cold sites and using torpor the animals conserve energy relative to the amounts that they would expend if they stayed in warm roosts and stayed euthermic, even if they huddled together at these already warm sites and warmed them up to temperatures close to their lower critical levels. It is suggested that the animals continue foraging each night, and despite reduced intakes relative to midsummer are able to deposit fat because of their reduced expenditures in the day.

It is known that during the pre-hibernal period many small insectivorous bats do roost in cold sites. For example, greater horseshoe bats (Rhinolophus ferrumequinum) in England in October are found in roosts at 8.5-12.5 (Ransome, 1971). However, it is unclear whether bats actively choose these sites because they are cold, or whether they select them because no warmer sites are available in this area at this time of year. It is also known that bats exposed to low temperatures during the pre-hibernal period are more likely to enter torpor than bats in the summer (Stones \& Weibers, 1967), as has been recorded in other hibernating mammals (Kalabukhov, 1960). In Myotid bats (Myotis lucifugus, M. thysanodes and $M$. yumanensis) there appears to be a change in the physiological response to low temperature which occurs over a relatively short period (14 d) during autumn (O'Farrell \& Studier, 1970). However, the functional significance of this use of torpor during the autumn is obscure and may reflect only 'a physiological reorientation preparatory for hibernation' (O'Farrell \& Studier, 1970), consistent with the suggestion of Menaker (1962) that a period of physiological preparation is necessary before animals are able to enter hibernation. It is not known whether bats exposed to low temperatures for protracted periods at this time of year enter torpor for long enough to make a saving relative to the expenditure they would have if they were to select much warmer roost sites, although theoretical calculations indicate sufficient savings could be made by prolonged torpor (Ewing et al. 1970).

In the present paper we shall present four tests of the 'cold roost and torpor use hypothesis' which are detailed as follows. First, if bats are given a choice of temperatures at which to roost, do they choose consistently colder sites in the pre-hibernal period than they do in midsummer? Second, if bats are placed in the cold during the day in the prehibernal period, do they enter torpor compared with ones placed in the warm during the same period? Third, if bats placed in the cold do enter torpor, do they do this for long enough to save energy relative to those placed in the warm? Finally, if they do save energy, is the saving sufficient to affect the lipid reserve dynamics of the bats?

\section{Study species}

Observations were made on eight brown long-eared bats (Plecotus auritus) during the pre-hibernal period (OctoberNovember) and nine different individual bats of the same species during the summer (June). The brown long-eared bat is the third commonest species of bat in Europe (Stebbings \& Griffith, 1986). It is found throughout northern Europe from latitudes of about $60^{\circ} \mathrm{N}$ to about $40^{\circ} \mathrm{N}$. At Aberdeen $\left(57^{\circ} \mathrm{N}\right)$, therefore, it is at about the northern limit of its range (Speakman et al. 1991). In the wild it feeds predominantly on moths (Swift \& Racey, 1983; Rydell, 1989) which it may glean from surfaces (Anderson \& Racey, 1991). The bats studied in summer were all pregnant females. The pre-hibernal bats were all post-lactational females. When not involved in these experiments the bats were kept in a large indoor room measuring approximately $3 \mathrm{~m} \times 3 \mathrm{~m} \times 3 \mathrm{~m}$ in which they could fly freely. The room was maintained at $20-25^{\circ}$ in both seasons, but in summer the bats were exposed to a long photophase $(18 \mathrm{~h}$ light $-6 \mathrm{~h}$ dark) and in the pre-hibernal phase were exposed to a short photophase ( $8 \mathrm{~h}$ light-16h dark). These periods of exposure were approximately the natural photoperiods at the times that the observations were made (June and OctoberNovember respectively). Individual bats were identified using numbered metal forearm bands (British Mammal Society, London, UK). Food (mealworms; Tenebrio sp.) and water were continuously available to the bats as were two 
wooden roost boxes (approximately $150 \mathrm{~mm} \times 150 \mathrm{~mm} \times$ $100 \mathrm{~mm}$ ). When required for measurements, bats were removed from the roost boxes by hand and transported to the laboratory $(2 \mathrm{~min}$ ) in cloth bags. The bats were brought into captivity under licence from Scottish Natural Heritage from roosts in the Grampian region of Scotland, and were returned to their roost sites on completion of the experiments.

\section{Test one: temperature choice}

During thermal-choice experiments the bats were placed into a thermal-choice chamber. The chamber was made of wood and measured $50 \mathrm{~mm}$ across, $100 \mathrm{~mm}$ high and $1.25 \mathrm{~m}$ long. The walls were abraded to provide a rough surface on which the bats could hang. The chamber had a Perspex top which had $10 \mathrm{~mm}$ holes drilled into it to avoid condensation. The chamber was surrounded by four water tanks which were maintained at temperatures between 0 and $60^{\circ}$. This produced a temperature gradient within the chamber from one end to the other. Marks were placed on the Perspex lid of the chamber at $50 \mathrm{~mm}$ intervals $(n 24)$ and the temperature inside the chamber was measured before and after each measurement period using a thermistor probe attached to a data logger (Grants squirrel; Grants Instruments Ltd, Cambridge, UK). The range of temperatures available to the bats varied from day to day depending in part on the room temperature. The average temperature across the locations varied from 10 to $44^{\circ}$. The range of measurements at each location is presented in Fig. 2. By recording the location of a bat in the chamber on any particular day it was possible to determine the temperature it had selected.

Each bat was placed in the chamber on its own at approximately 09.00 hours. The bats were encouraged to explore the chamber by making them move up and down it. They were then removed, and placed back in the chamber either at the cold or hot end and left for a period of $6 \mathrm{~h}$. The position of the bat was recorded at $15 \mathrm{~min}$ intervals throughout this period, ignoring the first $15 \mathrm{~min}$ after being placed in the

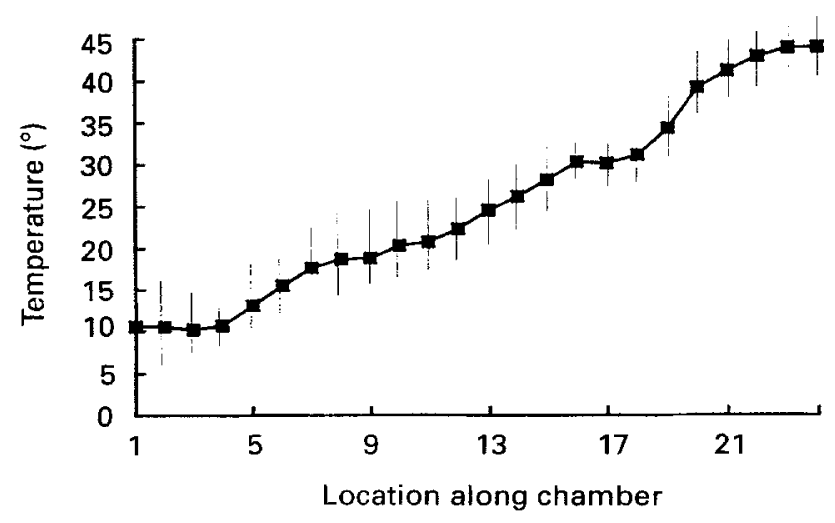

Fig. 2. Average temperatures at each location along a thermal choice chamber measured across $16 \mathrm{~d}$. The temperatures available to the bats varied from approximately $10^{\circ}$ at one end to $44^{\circ}$ at the other. The locations were marks placed at $50 \mathrm{~mm}$ intervals along the lid of the chamber. Points are averages and ranges represented by vertical bars. For details of procedures, see p. 125. chamber. Each bat was placed in the chamber on two separate occasions (entered at the cold and hot ends, with order randomized) and thus generated forty-eight observations of the temperature it had selected from those available. Data were pooled across all the individuals.

During summer the bats chose to roost predominantly in the hot part of the choice chamber, generally between 30 and $38^{\circ}$ (Fig. 3(a)). There were occasional excursions into the colder part of the chamber, but bats did not rest there for prolonged periods. The modal choice was $34.5^{\circ}$. In contrast, during the pre-hibernal period the animals chose most frequently to rest in the colder part of the chamber (Fig. 3(b)). The modal temperature selected at this time of year was $10.5^{\circ}$, which was among the lowest temperatures available to the bats. We do not know if the bats would have selected colder temperatures had they been available. Although the pre-hibernal bats chose most frequently to rest in the cold end of the chamber, some individuals did spend
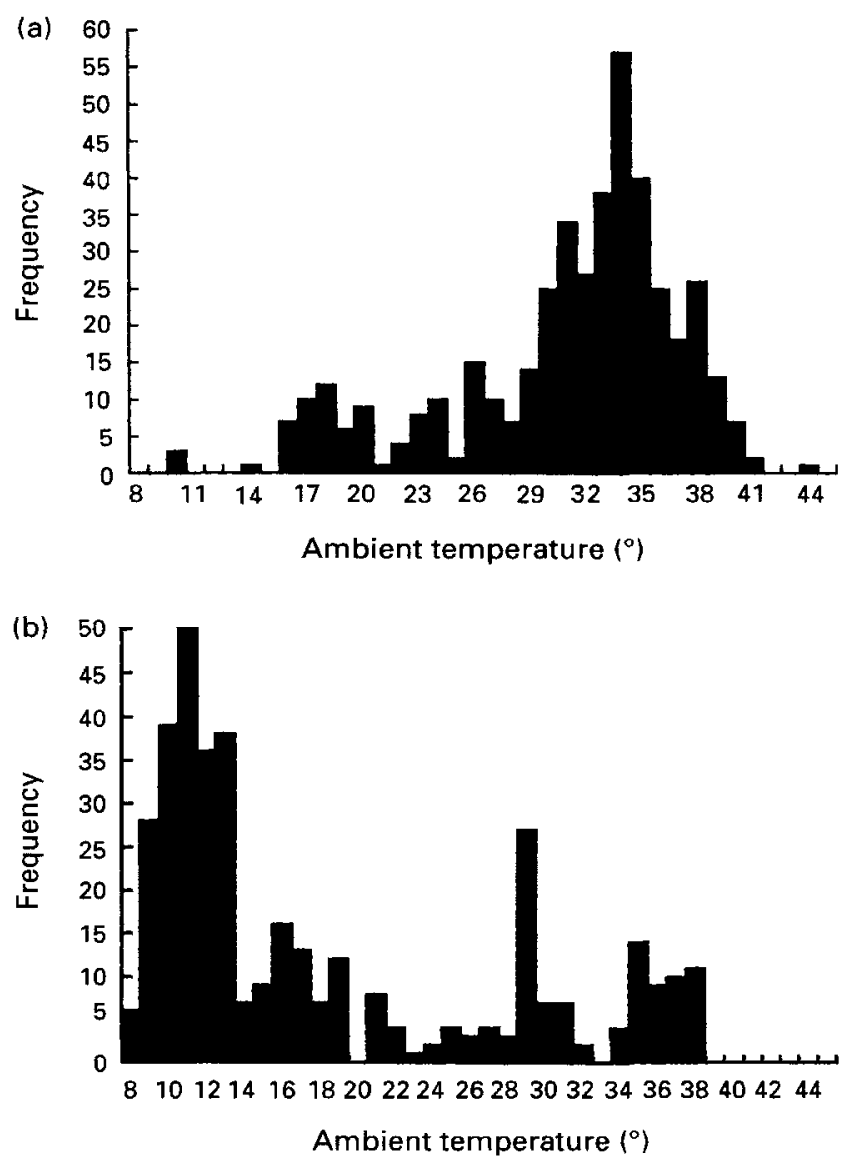

Fig. 3. (a) Frequency histogram showing the ambient temperatures in the locations selected by nine brown long-eared bats (Plecotus auritus) when in a thermal-choice chamber during summer. Each bat was observed for a period of $12 \mathrm{~h}$ in two separate trials each lasting $6 \mathrm{~h}$. Locations, which were marks placed at $50 \mathrm{~mm}$ intervals along the lid of the chamber, were recorded every $15 \mathrm{~min}$. (b) Frequency histogram showing the ambient temperatures in the locations selected by eight brown long-eared bats in the pre-hibernal period (OctoberNovember). For details of procedures, see p. 125. 
time in the warm parts of the chamber for periods up to several hours.

Once bats had settled down in the chamber they tended not to move for the remainder of the observation period. Although observations were made at $15 \mathrm{~min}$ intervals throughout the full $6 \mathrm{~h}$, it is clear that during each trial the bats actually only made a single choice about where to roost. Moreover, each bat was observed twice, further enhancing the potential pseudoreplication in the data. To avoid these problems in testing the significance of the thermoselection behaviour between the summer and pre-hibernal periods, we took the average temperature that had been selected by each bat across all the observations for the two measurement periods for that individual, and then compared these means across the summer ( $n 9)$ and pre-hibernal periods ( $n$ 8). The difference was significant $\left(t_{15} 3.48, P<0.001\right)$. These findings therefore support the hypothesis that during the pre-hibernal period brown long-eared bats choose colder roost sites than they do during the summer.

\section{Test two: do bats placed in the cold enter torpor?}

Monitoring body temperature of long-eared bats using internally-placed thermosensitive radiotransmitters is not feasible because the animals are too small (7-11 g) to implant the smallest available temperature-sensitive transmitter $(0.9-1.3 \mathrm{~g})$. To detect torpor we placed bats into a respirometry chamber and continuously monitored their $\mathrm{O}_{2}$ consumption. We detected the use of torpor from the massive reduction in $\mathrm{O}_{2}$ consumption which accompanies the relaxation of temperature regulation. A typical trace to illustrate this phenomenon is shown in Fig. 4.

The respirometry chamber was cylindrical in shape and had a diameter of $100 \mathrm{~mm}$. It was $200 \mathrm{~mm}$ long and therefore had an internal volume of $630 \mathrm{ml}$. The flow-rate through the chamber was regulated by a flow controller at $200 \mathrm{ml} / \mathrm{min}$. Air coming into the chamber from outside the building was dried using silica gel and then metered. Air leaving the chamber was also dried. $\mathrm{O}_{2}$ content of the incurrent and excurrent gases was measured using a dual-channel $\mathrm{O}_{2}$ analyser (model S3A; Applied Electrochemistry, Pittsburg, PA, USA). $\mathrm{O}_{2}$ consumption was estimated from the difference in the proportional $\mathrm{O}_{2}$ content between incurrent and excurrent gases multiplied by the flow-rate.

The chamber was located inside an incubator which was set at either $30^{\circ}$ or $7^{\circ}$. Individual bats were weighed and then placed in the chamber at approximately 18.00 hours, which was approximately $2 \mathrm{~h}$ before the onset of the dark phase in their roost. A weighed quantity of food (mealworms) and water were available in the chamber. Each bat was measured at both temperatures. The order in which bats were exposed to temperature was randomized. Measurements were made for $24 \mathrm{~h}$.

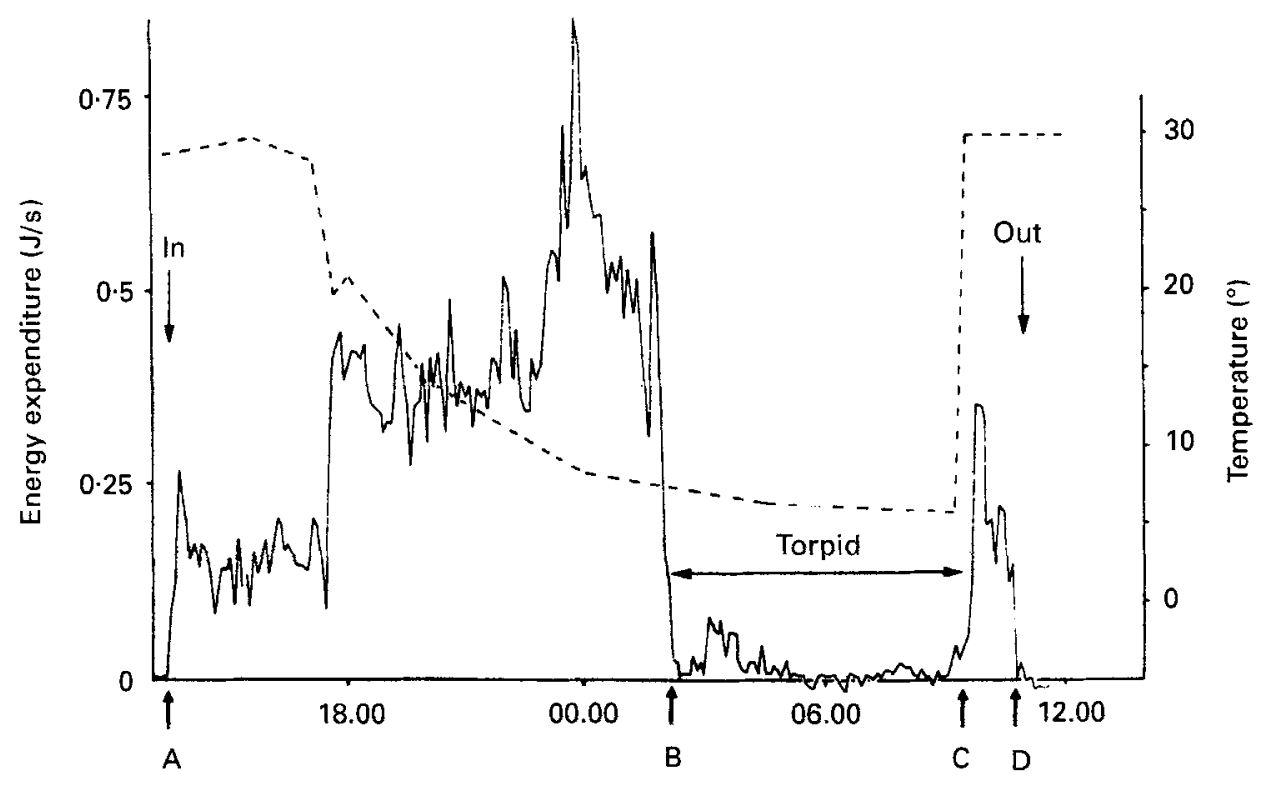

Time of day (hours)

Fig. 4. Typical time-course of metabolic rate in a small insectivorous bat (in this case, a common pipistreile, Pipistrellus pipistrellus) to illustrate the large reduction in metabolism that accompanies torpor. The bat was placed into the chamber at point $A$. During the next $3 \mathrm{~h}$ the chamber temperature was maintained at $30^{\circ}$ and the metabolic rate remained stable. Between 17.00 and 02.00 hours the ambient temperature was reduced and the metabolic rate of the bat increased to maintain body temperature. However, at point $B$, the bat abandoned euthermic temperature regulation and entered torpor. The metabolic rate was very low during this period and occasionally fell below the recorder sensitivity, giving negative readings. At point $\mathrm{C}$, the temperature was increased and the bat was aroused. The metabolic rate increased and approximately $1 \mathrm{~h}$ later at $\mathrm{D}$ the bat was removed. (-), Energy expenditure; (- - -), ambient temperature. (After Racey \& Speakman, 1987.) 
Since the flow-rate through the chamber was fast relative to the chamber volume, the clearance time was relatively fast (approximately $5 \mathrm{~min}$ ). Thus, records of torpor accurately reflect the duration spent in torpor by the animals ( $\pm 10 \mathrm{~min}$ ). All eight bats entered torpor when placed in the chambers at $7^{\circ}$, but none of them entered torpor at $30^{\circ}$. The duration of time spent in torpor varied between 8.8 and $18.7 \mathrm{~h}$, and averaged $14.1 \mathrm{~h}$. These time periods are long compared with the time sensitivity of the monitoring system. In all cases the bats spontaneously aroused before the end of the measurement period, even though the temperature in the chamber was stable throughout the experiment. These findings therefore support the suggestion that pre-hibernal bats will enter a daily torpor if they are in a roost site that is at low temperature.

\section{Test three: does the use of torpor at low temperatures result in an energy saving relative to roosting in the warm?}

We did not know the RQ for these bats, and therefore converted the measured $\mathrm{O}_{2}$ consumption to energy using an assumed RQ of 0.8 (Speakman \& Racey, 1987). There was a strong negative relationship between the total daily energy expended at $7^{\circ}$ and the time spent by the bats in torpor (Fig. 5). The least-squares-fit regression equation: energy expenditure $(\mathrm{kJ})=34.8-1.43$ time in torpor $(\mathrm{h})$, explained $56.7 \%$ of the variation in daily energy expenditure $\left(F_{1,7} 7.87, P=0.031\right)$. This equation suggests that if a long-eared bat did not enter torpor at $7^{\circ}$ its daily energy expenditure would average $34.8 \mathrm{~kJ}$. However, if it remained torpid for $24 \mathrm{~h}$ its energy expenditure would only be $0.5 \mathrm{~kJ}(34.8-24 \times 1.43)$, approximately 60 -fold lower. This illustrates the profound energy saving that animals can make by remaining torpid for the entire $24 \mathrm{~h}$. The estimated energy requirement for long-eared bats spending their entire time torpid is similar to the estimated requirements for continuously torpid pipistrelles ( $P$. pipistrellus), based on mass dynamics and food intake $(0.95 \mathrm{~kJ} / \mathrm{d})$ and direct measurements of torpid metabolic rates $(0.45 \mathrm{~kJ} / \mathrm{d}$; Speakman \& Racey, 1989).

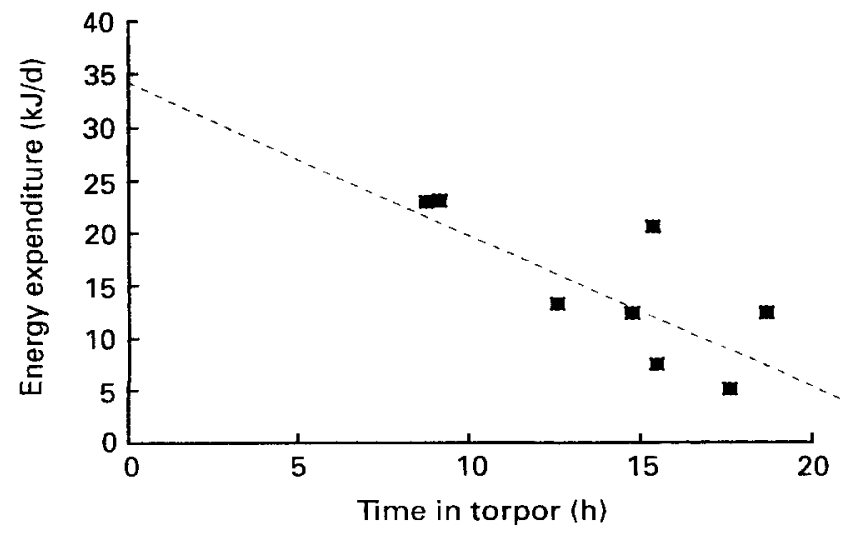

Fig. 5. Daily energy expenditure of eight brown long-eared bats (Plecotus auritus) measured at an ambient temperature of $7^{\circ}$ as a function of the time spent in torpor. There was a significant negative relationship (- - -). The longer bats spent in torpor the lower their total daily energy requirements.
However, the bats in this experiment at $7^{\circ}$ did not enter torpor for $24 \mathrm{~h}$, the daily energy expenditure was therefore higher than expected for continuous torpor and varied from $5.1 \mathrm{~kJ}$ to $23.1 \mathrm{~kJ}$, averaging $14.7 \mathrm{~kJ}$. The energy expenditure of the bats at $30^{\circ}$ was less variable because they did not enter torpor. The daily energy expenditure varied between $18.4 \mathrm{~kJ}$ and $23.7 \mathrm{~kJ}$ and averaged $21.9 \mathrm{~kJ}$. On average, therefore, the bats exposed to $7^{\circ}$ expended $7.2 \mathrm{~kJ} / \mathrm{d}$ less than the bats at $30^{\circ}$, a saving which they achieved by entering torpor (difference between warm and cold: ANOVA, $F_{1,14} 7 \cdot 67$, $P=0.015$ ). Interpolating the mean expenditure observed at $30^{\circ}$ on the relationship between energy expenditure at $7^{\circ}$ and time spent torpid (Fig. 5) suggests that to make a saving in the cold, relative to the expenditure in the warm, the bats would need to remain torpid for at least $9.05 \mathrm{~h}$. Seven of the eight bats observed in the cold spent longer than this in torpor.

These findings strongly support the suggestion that prehibernal bats in the cold can make a saving over roosting in warm locations by the use of torpor. By spending on average $14 \mathrm{~h}$ in torpor the bats in the cold reduced their daily roosting requirements by about one-third compared with the demands they would have had if they had selected a roost at $30^{\circ}$.

\section{Test four: is the energy saving in the cold sufficient to affect the body mass dynamics of these bats?}

The final question to be answered is what effect these savings have on the energy and mass balance of the animals when they are in the respirometry chamber. At the end of each $24 \mathrm{~h}$ respirometry session the bats were removed and reweighed. The remaining uneaten food was also removed along with any faeces produced by the animals. The faeces and samples of the mealworms were dried in an oven at $60^{\circ}$ for $10 \mathrm{~d}$ until they had reached constant mass. There was no significant difference in the wet weight of mealworms that was offered to the bats in the warm and in the cold (bats in warm 2.7 (SD 0.53) g, $n 8$; bats in cold 2.46 (SD 0.35) g, $n 8$; ANOVA; $\left.F_{1,14} 1 \cdot 19, P=0.574\right)$. In addition, there was no significant difference in the weights of mealworms remaining after $24 \mathrm{~h}$ (bats in warm 1.66 (SD 0.73) g, $n$ 8; bats in cold 1.40 (SD 0.86) g, $n$ 8; ANOVA, $F_{1,14} 0.45, P=0.514$ ). Consequently, the wet weight of mealworms consumed by the bats in the two conditions was also not significantly different (bats in warm 1.05 (SD 0.34) $\mathrm{g}, n$ 8; bats in cold 1.07 (SD 0.77) g, $n 8$; ANOVA, $F_{1,14} 0 \cdot 1, P=0.95$ ). On average the bats ate approximately $45 \%$ of the food that they were initially offered in both conditions. The DM content of the mealworms was 449.5 (SE 15.9) $\mathrm{g} / \mathrm{kg}$ ( $n$ 16), which is very similar to the DM content of $465 \mathrm{~g} / \mathrm{kg}$ reported by O'Farrell et al. (1971) and our own previous estimates of $414 \mathrm{~g} / \mathrm{kg}$ (Speakman \& Racey, 1989) and $389 \mathrm{~g} / \mathrm{kg}$ (Webb et al. 1993). We applied this DM content to the foodconsumption estimates to evaluate the dry mass of mealworms that the bats had ingested. Dry mass consumption averaged $0.47(\mathrm{SD} 0.15) \mathrm{g}(n 8)$ for the bats held at $30^{\circ}$ and $0.48(\mathrm{SD} 0.34) \mathrm{g}(n 8)$ when they were held at $7^{\circ}$. Estimates of the energy content of mealworm larvae average $25.5 \mathrm{~kJ} / \mathrm{g}$ dry weight (Neuheuser \& Brisbin, 1964; O'Farrell et al. 1971; Speakman \& Racey, 1989; Barclay et al. 1991; Webb 
et al. 1993), therefore the gross energy intake when the bats were in the warm averaged $11.93(\mathrm{SD} 3.92) \mathrm{kJ} / \mathrm{d}$ and in the cold it averaged $12.16($ SD 8.82$) \mathrm{kJ} / \mathrm{d}$.

In the cold the bats produced approximately 3 -fold more faeces than the bats in the warm, despite eating almost identical amounts of the food. On average, in the warm the bats produced 0.063 (SD 0.034) $\mathrm{g}$ faeces (wet mass; $n$ 8) during the $24 \mathrm{~h}$, while in the cold they produced 0.25 (SD 0 -18) $\mathrm{g}(n 8)$. The water content of the faeces averaged $612 \mathrm{~g} / \mathrm{kg}$ and the dry mass of faeces produced averaged 0.031 (SD 0.018) $\mathrm{g}$ in the warm and 0.093 (SD 0.075) $\mathrm{g}$ in the cold. The difference marginally failed to reach significance $\left(F_{1,14} 4.21, P=0.059\right)$. However, the calculated dry mass absorption efficiencies between the two conditions were significantly different. On average, the bats in the warm absorbed 93.5 (SD 3.3) \% ( $n$ 8) of the food they ingested, but when they were in the cold they only absorbed 75.7 (SD 14.8) \% ( $n$ 8; ANOVA on arcsin square root transformed proportions, $F_{1,14} 13.94, P=0.002$ ). Brown long-eared bats kept at $25^{\circ}$ had an intermediate apparent absorption efficiency averaging 85.3 (range 72.4-90.4) \% (Webb et al. 1993). The absorption efficiency of $M$. thysanodes was $90.8 \%$ and that of $M$. lucifugus was $91.2 \%$ when feeding on mealworms at ambient temperatures of $18-24^{\circ}$ during autumn (O'Farrell et al. 1971). Absorption efficiency averaged $91.0 \%$ in Lasiurus cinereus (Brisbin, 1966) and $88.6 \%$ in Lasionycteris noctivagans (Neuheuser \& Brisbin, 1969) feeding on mealworms during the summer. All these estimates are similar to the levels reported here for bats held at $30^{\circ}$. In contrast, the absorption efficiency of hibernating Pipistrellus pipistrellus housed at $-2-+11$ (mean 4$)^{\circ}$ was $82.8 \%$ (Speakman \& Racey, 1989), which is closer to the estimated absorption efficiency for $P$. auritus held at $7^{\circ}$, supporting the suggestion that absorption efficiency is reduced at low ambient temperatures.

The significant difference in absorption efficiency between the warm and cold conditions suggests that when bats are torpid the efficiency of their digestion is impaired. This is consistent with observations that below temperatures of $7^{\circ}$ intrinsic intestinal motility of big brown bats (Eptesicus fuscus) ceased (Studier et al. 1976). The reduction in digestive efficiency with body temperature is consistent with the idea that a major component of endothermic resting metabolic rate is the activity of the alimentary system (Weiner, 1989; Hammond \& Diamond, 1997) and agrees with observations that rattlesnakes (Crotalus cerastes) rapidly up-regulate their gut function when they feed, leading to enormous increases in their resting metabolic rates (Secor et al. 1994). The variability in absorption efficiency in the cold was about 5 -fold greater than that in the warm $\left(F_{7,7} 5.67, P=0.03\right)$, but the absorption efficiency was not related to the duration of time the bats spent torpid $\left(r^{2} 0.02, F_{1,7} 0 \cdot 10, P=0.768\right)$.

Although absorption efficiency differed between the warm and cold conditions, the effect on net energy absorption was not significant. Using an estimate of $19.54 \mathrm{~kJ} / \mathrm{g}$ for the energy content of faeces produced by $P$. auritus when feeding on mealworms (Webb et al. 1993), on average when the bats were in the warm they absorbed 11.32 (SD 3.65) $\mathrm{kJ} / \mathrm{d}(n 8)$ and when they were in the cold they absorbed 10.35 (SD 8.0) kJ/d ( $n 8$; ANOVA $F_{1,14} 0 \cdot 10, P=0.76$ ).
Net energy absorption was lower in both conditions than energy expenditure. On average, when the bats were in the warm they expended $21.86 \mathrm{~kJ}$, but had a net absorption of only $11.32 \mathrm{~kJ}$ (mean difference 10.54 (SD 5.05 ) kJ, $n 8$ ), whereas when they were in the cold they expended $14.68 \mathrm{~kJ}$ and had a net absorption of $10.32 \mathrm{~kJ}$ (mean difference 4.33 (SD 5.66$) \mathrm{kJ}, n$ 8). The difference in the shortfall between absorption and expenditure was significant $\left(F_{1,14} 5 \cdot 34\right.$, $P=0.037$ ). It is unclear why the bats in the chambers did not eat more food, as they generally only ate about $45 \%$ of what was initially provided. Possibly food intake was limited by the dynamics of the chamber. Many of the uneaten mealworms were found under the food pot in the base of the chamber where they were probably unavailable to the bats. However, whether they accumulated there after the bats had stopped feeding or became unavailable to the bats while they were still feeding, thus limiting intake, is unknown.

Given the different shortfalls in energy balance, one would anticipate that the bats in the warm would lose more body mass than the bats in the cold, and this was indeed the case. When they were in the warm the bats lost on average 1.15 (SD 0.25) g body mass ( $n$ 8), but when they were in the cold they only lost on average 0.36 (SD 0.22) $\mathrm{g}(n 8)$. Across all the measurements there was a significant positive relationship between the mass loss of an individual and the calculated energy shortfall between net energy absorption and energy expenditure (Fig. 6) for the same individual. The regression equation: energy shortfall $(\mathrm{kJ})=0.742+8.86$ mass loss $(\mathrm{g})$, explained $46.8 \%$ of the variation in energy shortfall $\left(F_{1,14} 12.31, P=0.003\right)$. The intercept of the regression did not differ from 0 as might be expected $(t 0.33$, $P=0.744$ ). The gradient indicated that the energy equivalence of wet mass loss was $8.86 \mathrm{~kJ} / \mathrm{g}$.

The energetic equivalence of the wet mass loss was considerably lower than might be anticipated if the mass loss had been assumed to comprise only fat (approximately $39 \mathrm{~kJ} / \mathrm{g}$ ) or only protein (approximately $25 \mathrm{~kJ} / \mathrm{g}$ ). This

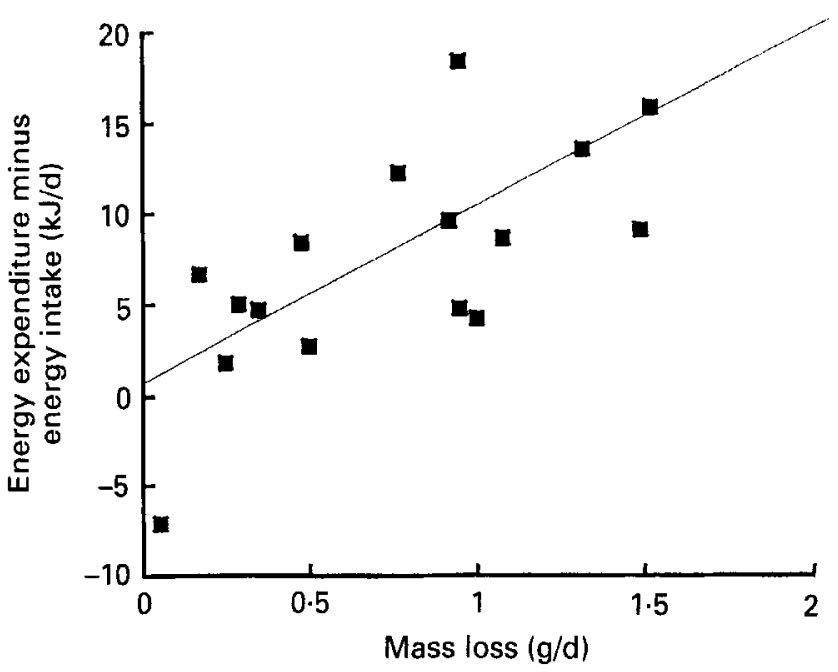

Fig. 6. Difference between energy expenditure and energy intake (calculated from the food intake and faecal production) $v$. body mass change over the same interval. There was a significant positive relationship $(-)$. When bats had a greater shortfall between intake and expenditure they also lost more body mass. 
suggests that when bats mobilize reserves they also mobilize and lose considerable quantities of water. In this instance, if the bats were drawing on fat to meet the energy shortfall, then approximately $80 \%$ of the mass they lost was water and only $20 \%$ fat. In contrast, if they were utilizing protein then water loss would account for $66 \%$ of the mass loss. Clearly, most of the observed mass changes were not of metabolizable body tissue but of associated water changes. These observations support our previous observations that when pipistrelle bats in hibernation lost body mass their relative body water content remained unaffected, indicating that approximately $70 \%$ of the mass lost was water (Speakman \& Racey, 1989). This phenomenon has important ramifications for attempts to construct energy budgets for bats which are not in steady-state body mass, when composition of body mass change is unknown but is assumed to reflect mobilization of stored energy. For example, if body mass changes were assumed to reflect mobilization of fat alone, the estimated energy utilization would be approximately 4-fold greater than the actual energy usage.

\section{Summary}

Brown long-eared bats placed in a thermal choice chamber chose to roost in significantly colder locations during the pre-hibernal period than they did during the summer. Prehibernal brown long-eared bats placed in respirometry chambers for $24 \mathrm{~h}$ at $30^{\circ}$ never fell torpid, and expended on average $21.9 \mathrm{~kJ} / \mathrm{d}$. The same bats placed in the same chamber at $7^{\circ}$ fell torpid for on average $14.1 \mathrm{~h}$ during the $24 \mathrm{~h}$ period. The impact of using this torpor was that on average the energy demands of the bats at $7^{\circ}$ were about $33 \%$ lower $(14.7 \mathrm{~kJ} / \mathrm{d})$ than those at $30^{\circ}$. The bats in the two conditions ate the same amounts of food but dry mass absorption efficiency was reduced in the bats that became torpid. Nevertheless, the energy content of the food absorbed also did not differ between the warm and cold conditions, and averaged $11.93 \mathrm{~kJ} / \mathrm{d}$ in the warm and $12.16 \mathrm{~kJ} / \mathrm{d}$ in the cold. This was only $45 \%$ of the food offered to the bats in the chambers. Why they did not eat more is unclear, but may have been related to the dynamics of the chamber. All the bats were in energy deficit over $24 \mathrm{~h}$. However, the lower energy expenditures of the bats at $7^{\circ}$ meant that they lost only on average $0.35 \mathrm{~g}$ body mass, whereas when they were at $30^{\circ}$ they lost on average $1.15 \mathrm{~g}$ mass. Across individuals and conditions the extent of mass loss was related to the shortfall between expenditure and intake; the energy equivalence was $8.86 \mathrm{~kJ} / \mathrm{g}$ mass loss. This indicates considerable correlated mobilization and loss of water occurs alongside mobilization of energy reserves.

\section{References}

Alerstam T (1990) Bird Migration. Cambridge: Cambridge University Press.

Anderson ME \& Racey PA (1991) Feeding behaviour of captive brown long-eared bats, Plecotus auritus. Animal Behaviour 42, $489-493$.

Avery MI (1985) Winter activity of pipistrelle bats. Joumal of Animal Ecology 54, 721-738.
Baker R (1980) The Mystery of Migration. London: Macdonald Futura Books.

Baker WW, Marshall SG \& Baker VB (1968) Autumn fat deposition in the evening bat (Nycticieus humeralis). Journal of Mammalogy 49, 314-317.

Barclay RMR, Dolan M \& Dyck A (1991) The digestive efficiency of insectivorous bats. Canadian Journal of Zoology 69, 18531856.

Beer JR \& Richards AG (1956) Hibernation of the big brown bat. Journal of Mammalogy 37, 31-41.

Berteaux D, Bergeron JM, Thomas DW \& Lapierre H (1996) Solitude versus gregariousness - do physical benefits drive the choice in overwintering meadow voles. Oikos 76, 330-336.

Brisbin IL (1966) Energy use by a captive Hoary bat. Journal of Mammalogy 47, 719-720.

Cameron M (1994) Monthly Digest of Statistics no. 585. London: Central Statistics Office, H. M. Stationery Office.

Daan S (1973) Activity during natural hibernation in three species of vespertilionid bats. Netherlands Journal of Zoology 23, 1-71.

Davis WH (1970) Hibernation: ecology and physiological ecology. In The Biology of Bats, vol. 3, pp. 265-300 [WA Wimsatt, editor]. New York: Academic Press.

Davis WH \& Hitchcock HB (1965) Biology and migration of the bat, Myotis lucifugus, in New England. Journal of Mammalogy 46, 296-313.

Ewing WG, Studier EH \& O'Farrell M (1970) Autumn fat deposition and gross body composition in three species of Myotis. Comparative Biochemistry and Physiology 36, 119-129.

Funakoshi K \& Uchida TA (1978) Studies on the physiological and ecological adaptations of temperate insectivorous bats. III Annual activity of the Japanese house dwelling bat, Pipistrellus abramus. Journal of the Faculty of Agriculture, Kyushu University 23, 95-115.

Geiser F \& Kenagy J (1988) Torpor duration in relation to temperature and metabolism in hibernating ground squirrels. Physiological Zoology 61, 442-449.

Hammond KA \& Diamond J (1997) Maximal sustained energy budgets in humans and animals. Nature 386, 457-462.

Hart JS (1957) Climatic and temperature induced changes in the energetics of homeotherms. Revue Canadienne de la Biologie 16, 133-174.

Heldmaier G (1989) Seasonal acclimatization of energy requirements in mammals: functional significance of body weight control, hypothermia, torpor and hibernation. In Energy Transformations in Cells and Organisms, pp. 130-139 [W Weiser and E Gnaiger, editors] New York: Springer.

Hock R (1951) The metabolic rates and body temperatures of bats. Biological Bulletin 101, 289-299.

Kahlabukhov NI (1960) Comparative ecology of hibernating mammals. Bulletin of the Museum of Comparative Zoology, Havard University 124, 45-74.

Karasov WH (1983) Wintertime energy conservation by huddling in antelope ground squirrels (Ammospermophilus leucurus). Journal of Mammalogy 64, 341-345.

Kayser C (1961) The Physiology of Natural Hibernation. New York: Pergamon Press.

Krulin GS \& Sealander JA (1972) Annual lipid cycle of the gray bat Myotis grisescens. Comparative Biochemistry and Physiology 42, 537-549.

Krzanowski A (1961) Weight dynamics of bats wintering in a cave at Pulawy (Poland). Acta Theriologica 4, 242-264.

Livoreil B \& Baudoin C (1996) Differences in food hoarding behaviour in two species of ground squirrels Spermophilus tridecemlineatus and Spermophilus spilosoma. Ethology Ecology and Evolution 8, 199-205.

Lyman CP (1954) Activity, food consumption and hoarding in hibernation. Journal of Mammalogy 35, 542-552. 
Neuheuser HN \& Brisbin IL (1964) Energy utilisation by a captive silver-haired bat. Bat Research News 10, 30-31.

O'Farrell MJ \& Bradley WG (1970) Activity patterns of bats over a desert spring. Journal of Mammalogy 51, 18-26.

O'Farrell MJ \& Studier EH (1970) Fall metabolism in relation to ambient temperature in three species of Myotis. Comparative Biochemistry and Physiology 35, 697-704.

O'Farrell MJ, Studier EH \& Ewing WG (1971) Energy utilisation and water requirements of captive $M$. lucifugus and M. thysandodes. Comparative Biochemistry and Physiology 39A, 549-552.

Oliver JE \& Fairchild RW (1984) The Encyclopedia of Climatology. New York: Von Nostrand Reinhold.

Ransome R (1971) The effect of ambient temperature on arousal frequency of the hibernating Greater Horseshoe bat (Rhinolophus ferrumequinum) in relation to site selection and the hibernation site. Journal of Zoology 164, 353-371.

Rydell J (1989) Food habits of northern (Eptesicus nilssoni) and brown long-eared (Plecotus auritus) bats in Sweden. Holarctic Ecology 12, 16-20.

Secor SM, Stein EJ \& Diamond J (1994) Rapid up-regulation of snake intestine in response to feeding - a new model of intestinal adaptation. American Journal of Physiology 266, G695-G705.

Speakman JR (1997) Doubly-labelled Water: Theory and Practice. London: Chapman \& Hall.

Speakman JR \& Racey PA (1987) The energetics of pregnancy and lactation in the brown long-eared bat (Plecotus auritus). In Recent Advances in the Study of Bats, pp. 367-393 [MB Fenton, PA Racey and JMV Rayner, editors]. Cambridge: Cambridge University Press.

Speakman JR \& Racey PA (1989) Hibernal ecology of the pipistrelle bat: energy expenditure, water requirements and mass loss - implications for survival and the function of winter emergence flights. Journal of Animal Ecology 58, 797-813.

Speakman JR, Racey PA, Catto CMC, Webb PI, Swift SM \& Burnett AM (1991) Minimum population estimates and densities of bats in NE Scotland, near to the Northern borders of their distributions, during summer. Journal of Zoology 225, 327-345.

Stebbings RE \& Griffith F (1986) Distribution and Status of Bats in Europe. Huntingdon, Cambs.: Institute of Terrestrial Ecology.
Stones RC \& Weibers JE (1967) Temperature regulation in the little brown bat, Myotis lucifugus. In Mammalian Hibernation, vol. 3, pp. 97-109 [KC Fischer, editor]. New York: Oliver and Boyd.

Strijkstra AM \& Daan S (1997) Sleep during arousal episodes as a function of prior torpor duration in hibernating European ground squirrels. Journal of Sleep Research 6, 36-43.

Studier EH, Behrend TA \& Freed AL (1976) Effect of temperature on intrinsic intestinal motility in a hibernator. Journal of Thermal Biology 1, 149-151.

Swift SM \& Racey PA (1983) Resource partitioning in two species of vespertilionid bats (Chiroptera) occupying the same roost. Journal of Zoology 200, 249-259.

Thomas DW (1995) The physiological ecology of hibernation in vespertilionid bats. Symposia of the Zoological Society of London 67, 233-244.

Thomas DW \& Cloutier D (1992) Evaporative water loss by hibernating little brown bats, Myotis lucifugus. Physiological Zoology 65, 443-456.

Thomas DW, Dorais M \& Bergeron JM (1990) Winter energy budgets and the cost of arousals for hibernating little brown bats, Myotis lucifugus. Journal of Mammalogy 71, 475-479.

Thomas DW \& Geiser F (1997) Periodic arousals in hibernating mammals: is evaporative water loss involved? Functional Ecology 11, 585-591.

Twente JW \& Twente JA (1965) Regulation of hibernating periods by temperature. Proceedings of the National Academy of Sciences USA 54, 1058-1061.

Wang LCH (1978) Energetic and field aspects of mammalian torpor: the Richardsons ground squirrel. In Strategies in the Cold, pp. 109-145 [LHC Wang and JW Hudson, editors]. New York: Academic Press.

Webb PI, Speakman JR \& Racey PA (1993) Defecation, apparent absorption efficiency, and the importance of water obtained in the food for water balance in captive brown long-eared (Plecotus auritus) and Daubenton's (Myotis daubentoni) bats. Journal of Zoology 230, 619-628.

Weiner J (1989) Metabolic constraints on mammalian energy budgets. Acta Theriologica 34, 3-35.

Witter MS, Cuthill IC \& Bonser KHC (1994) Experimental investigations of mass specific predation risk in the European Starling Sturnus vulgaris. Animal Behaviour 48, 201-222. 